\title{
Potential of combination of DCE-MRI and DWI with serum CA125 and CA199 in evaluating effectiveness of neoadjuvant chemotherapy in breast cancer
}

\author{
Jun Zhang ${ }^{1}$, Yongbo Huang ${ }^{2}$, Jianghui Chen ${ }^{3}$, Xia Wang ${ }^{3}$ and Hongyu Ma ${ }^{2 *}$
}

\begin{abstract}
Background: To determine the potential of the combination of DCE-MRI imaging method with DWI and serum CA125 and CA199 levels in the evaluation of the efficacy of neoadjuvant chemotherapy in breast cancer patients.

Methods: Sixty-five breast cancer patients who received neoadjuvant chemotherapy in our hospital from April 2016 to April 2017 were selected as research subjects. The patients received 4 courses of neoadjuvant chemotherapy. Lesions were monitored using DCE-MRI and DWI, while ELISA was used to measure the serum expression levels of the tumour markers CA125 and CA199. The patients were divided into the remission group and ineffective group based on pathological diagnosis.

Results: There were significant differences in $\mathrm{K}_{\mathrm{e} p}, \mathrm{~K}_{\text {trans, }}, A D C_{\text {min, }} A D C_{\text {mean, }}$ tumour volume, and serum levels of CA125 and CA199 in patients in the remission group, before and after neoadjuvant chemotherapy, and there were significant differences in post-chemotherapy values of these indexes between the remission group and the ineffective group $(p<0.01)$.

Conclusion: Combination of DCE-MRI diagnostic imaging with DWI can directly reflect the lesions in breast cancer patients after neoadjuvant chemotherapy. Serum levels of CA125 and CA199 levels are useful for evaluation of the impact of neoadjuvant chemotherapy on breast cancer patients, including risk of cancer cell metastasis and changes in some small lesions.
\end{abstract}

Keywords: Breast cancer, CA125, CA199, DCE-MRI, DWI, Neoadjuvant chemotherapy

\section{Introduction}

Breast cancer is one of the common gynecological diseases with high morbidity and mortality, and it is a serious threat to the health of women [1-3]. Neoadjuvant chemotherapy refers to systemic chemotherapy before surgical resection or local radiotherapy on the lesions. It reduces the risk of cancer cell metastasis to a certain

\footnotetext{
* Correspondence: qzmz25@163.com

${ }^{2}$ CT Radiology, Gaomi People's Hospital, Gaomi 261500, Shandong Province, China

Full list of author information is available at the end of the article
}

extent, thereby facilitating follow-up intervention to control the disease conditions of the patients [4-6]. Based on years of clinical experience, neoadjuvant chemotherapy is often used in clinical intervention in patients with tumours [7-9]. With advancements in technology, the conventional MRI imaging method and measurement of levels of tumour markers are also used for evaluating the therapeutic effect of neoadjuvant chemotherapy on breast cancer $[10,11]$. In this study, the potential value of neoadjuvant chemotherapy in the evaluation of the effect of neoadjuvant chemotherapy in breast cancer was

C C The Author(s). 2021 Open Access This article is licensed under a Creative Commons Attribution 4.0 International License, which permits use, sharing, adaptation, distribution and reproduction in any medium or format, as long as you give appropriate credit to the original author(s) and the source, provide a link to the Creative Commons licence, and indicate if changes were made. The images or other third party material in this article are included in the article's Creative Commons licence, unless indicated otherwise in a credit line to the material. If material is not included in the article's Creative Commons licence and your intended use is not permitted by statutory regulation or exceeds the permitted use, you will need to obtain permission directly from the copyright holder. To view a copy of this licence, visit http://creativecommons.org/licenses/by/4.0/. The Creative Commons Public Domain Dedication waiver (http://creativecommons.org/publicdomain/zero/1.0/) applies to the data made available in this article, unless otherwise stated in a credit line to the data. 
evaluated using the diagnostic imaging method of DCEMRI and DWI in combination with serum levels of CA125 and CA199. The study was aimed at providing useful information for the improvement of clinical diagnosis and treatment of breast cancer.

\section{Methods}

\section{General information on subjects}

This was a prospective study on 65 breast cancer patients who received neoadjuvant chemotherapy in our hospital from April 2016 to April 2017. Table 1 shows the general information on the patients.

\section{Inclusion and exclusion criteria}

\section{Inclusion criteria}

The included patients were those who had a detailed understanding of the aim of the study and signed informed content to participate in it, as well as patients who had no contraindication to imaging examinations used. Moreover, patients who had no other malignant tumours, and patients who accepted neoadjuvant treatment, were included in the study.

\section{Exclusion criteria}

Patients whose clinical data were incomplete, and patients whose conditions were complicated with inflammation and other diseases which might have a serious influence on the results of this study, were excluded. Moreover, patients who did not cooperate with clinical follow-up were excluded.

\section{Neoadjuvant chemotherapy regimens}

The patients received chemotherapy with CEF (or CTF) regimen. For this purpose, the patients were treated with epirubicin, cyclophosphamide and docetaxel at doses of 600,60 and $75 \mathrm{mg} / \mathrm{m}^{2}$, respectively (within the same day) via an intravenous drip, once a week, with 3 weeks as one complete course. In all, the patients received four courses of chemotherapy.

Table 1 General information of patients

\begin{tabular}{|c|c|c|}
\hline Parameters & & Data \\
\hline Number of patients & & 65 \\
\hline Age (years old) & & $35-55$ \\
\hline Average age (years old) & & $46.6 \pm 9.1$ \\
\hline Height (cm) & & $163.3 \pm 5.6$ \\
\hline Weight (kg) & & $53 \pm 5.3$ \\
\hline Body mass index $\left(\mathrm{kg} / \mathrm{m}^{2}\right)$ & & $25.6 \pm 3.9$ \\
\hline $\begin{array}{l}\text { TNM staging } \\
\text { (number of patients) }\end{array}$ & $\begin{array}{l}\text { T1 } \\
\text { T2 } \\
\text { T3 }\end{array}$ & $\begin{array}{l}13 \\
33 \\
19\end{array}$ \\
\hline
\end{tabular}

\section{Parameters measured}

\section{Assay of serum markers}

Serum expression levels of CA125 and CA199 in patients were assayed using ELISA. Fasting venous blood $(5 \mathrm{~mL})$ collected from each patient was taken up in a sterile centrifuge tube. The blood samples were heated in a water bath at $37^{\circ} \mathrm{C}$ and centrifuged at $3500 \mathrm{rpm}$ for $3 \mathrm{~min}$ to obtain serum samples. The serum expression levels of CA125 and CA199 were assayed using ELISA kits (Abcam, UK).

The GE Signa HDxt1.5 T scanner (Car-Escorting Corporation, Chicago, USA) with a phase-controlled coil of 8 channels was used to carry out DWI and DCE-MRI on the patients.

\section{Measurement of DCE-MRI}

The conditions used were sequence of T1WI-VIBE, TR of $5000 \mathrm{~ms}$, TE of $30 \mathrm{~ms}$, FOV of $30 \times 30 \mathrm{~cm}^{2}$, pixel of 0.5 $\mathrm{mm} \times 0.5 \mathrm{~mm} \times 3.0 \mathrm{~mm}$, NEX of two times, layer thickness of $3.0 \mathrm{~mm}$, and layer spacing of $1.0 \mathrm{~mm}$. After obtaining the mask, channels for intravenous injection were established on the back of the hand of each patient and GdDTPA was used as a contrast agent, with an injection dose of $0.2 \mathrm{mmol} / \mathrm{kg}$ and injection rate of $2.5 \mathrm{~mL} / \mathrm{s}$. Thereafter, DCE-MRI was immediately performed, and the dynamic enhanced images were transferred to TISSUE 4D software to determine the location of tumours. The average value of lesions was taken after three measurements, and the pseudo-colour images were generated. Then, the following quantitative parameters were calculated:

1. Volume transfer constant $\left(\mathrm{K}_{\text {trans }}\right)$ was the velocity constant of intravascular contrast agent diffusing outside the blood vessels.

2. Rate constant $\left(\mathrm{K}_{\mathrm{ep}}\right)$ was the velocity constant of extravascular contrast agent penetrating into the blood vessels.

3. Volume fraction of extravascular extracellular space $\left(V_{e}\right)$ : This was calculated as shown below:

$$
V_{e}: \frac{\text { (Vascular volume }+ \text { extracellular space volume) }}{\text { Total volume }}
$$

\section{Measurement of DWI}

The patients were scanned using single-shot echo planar imaging technique, with SE-EPI sequence, under the following conditions: TR of $300 \mathrm{~ms}$, TE of $86.0 \mathrm{~ms}$, acquisition matrix of $320 \times 320$, FOV of 35, 18 layers, layer thickness of $4.0 \mathrm{~mm}$, layer spacing of $1.0 \mathrm{~mm}$ and NEX of 6 times. The ADC values were calculated under gradient factor $\mathrm{b}$ value at 0 or $1000 \mathrm{~s} / \mathrm{mm}^{2}$. 


\section{Assessment of effectiveness of neoadjuvant} chemotherapy in the two groups of patients

The patients were divided into the remission group and ineffective group, based on the pathological diagnosis. The quantitative parameters for DCE-MRI $\left(\mathrm{K}_{\mathrm{ep}}, V_{e}\right.$ and $\left.\mathrm{K}_{\text {trans }}\right)$; DWI apparent diffusion coefficients $\left(\mathrm{ADC}_{\min }\right.$ and $\mathrm{ADC}_{\text {mean }}$ ), tumour size, and serum expression levels of CA125 and CA199 were compared between the two groups before and after chemotherapy.

\section{Statistical analysis}

The calculation of sample size and analysis of data obtained in this study were carried out using the SPSS version 20.0 software (International Business Machines Corporation, NY, USA). Count data were statistically analysed using $X^{2}$ test, while measurement data were analysed with Student's $t$ test. Differences were assumed statistically significant at $p<0.05$.

\section{Results}

\section{Comparison of DCE-MRI quantitative parameters before} and after neoadjuvant chemotherapy

Table 2 shows a comparison of DCB-MRI quantitative parameters before and after neoadjuvant chemotherapy between the remission group and the ineffective group. There were no significant differences in $K_{e p}, K_{\text {trans }}$ and $V_{e}$ between the two groups before neoadjuvant chemotherapy $(p>0.05)$. However, there were significant changes in $K_{e p}$ and $\mathrm{K}_{\text {trans }}$ in the remission group after intervention, and there were significant differences in values of $K_{e p}$ and $\mathrm{K}_{\text {trans }}$ between the remission group and the ineffective group after neoadjuvant chemotherapy ( $p$ $<0.01)$.

\section{Comparison of DWI results before and after neoadjuvant chemotherapy}

Comparison of DWI results in the remission group and the ineffective group before and after neoadjuvant chemotherapy is shown in Table 3. Before chemotherapy, there were no significant differences in $\mathrm{ADC}_{\text {min }}$ and $\mathrm{ADC}_{\text {mean }}$ between the two groups $(p>0.05)$. However, there were significant differences in values of $\mathrm{ADC}_{\text {min }}$ and $\mathrm{ADC}_{\text {mean }}$ in the remission group before and after intervention, and there were significant differences in the values of these parameters between the remission group and the ineffective group after chemotherapy $(p<0.01)$.

\section{Tumour volume before and after neoadjuvant chemotherapy}

Figure 1 shows tumour volumes in patients before and after intervention. There was no significant difference in tumour volume of patients in the ineffective group before and after treatment $(p>0.05)$. However, after neoadjuvant chemotherapy, tumour volume of the remission group was significantly reduced, and there was a significant difference in the tumour volume between the two groups after neoadjuvant chemotherapy $(p<0.01)$.

\section{Serum CA125 levels of patients before and after neoadjuvant chemotherapy}

Figure 2 shows serum CA125 levels of patients before and after neoadjuvant chemotherapy. Before treatment, there was no significant difference in CA125 level between the two groups $(p>0.05)$. In contrast, after neoadjuvant chemotherapy, the CA125 level in the remission group was significantly lower than the corresponding level in the ineffective group $(p<0.01)$.

Table 2 Comparison of DCE-MRI quantitative parameters before and after neoadjuvant chemotherapy

\begin{tabular}{|c|c|c|c|c|c|c|}
\hline Indexes & Group & Number of cases & Before chemotherapy & After chemotherapy & $t$ & $P$ \\
\hline \multirow[t]{4}{*}{$\mathrm{K}_{\mathrm{ep}}(/ \mathrm{min})$} & Remission group & 39 & $1.79 \pm 0.5$ & $0.79 \pm 0.27$ & 9.32 & $<0.01$ \\
\hline & Ineffective group & 26 & $1.67 \pm 0.53$ & $1.51 \pm 0.53$ & 1.19 & $>0.05$ \\
\hline & $t$ & & 0.93 & 7.21 & & \\
\hline & $P$ & & $>0.05$ & $<0.01$ & & \\
\hline \multirow[t]{8}{*}{$\mathrm{K}_{\text {trans }}(/ \mathrm{min})$} & Remission group & 39 & $1.39 \pm 0.51$ & $0.67 \pm 0.29$ & & \\
\hline & Ineffective group & 26 & $1.27 \pm 0.51$ & $1.13 \pm 0.33$ & 6.52 & $<0.01$ \\
\hline & $t$ & & 0.93 & 5.93 & 1.24 & $>0.05$ \\
\hline & $P$ & & 0.36 & 0.00 & & \\
\hline & Remission group $V_{e}$ & 39 & $0.75 \pm 0.31$ & $0.77 \pm 0.19$ & 0.29 & $<0.01$ \\
\hline & Ineffective group $V_{e}$ & 26 & $0.83 \pm 0.33$ & $0.85 \pm 0.13$ & 0.29 & $>0.05$ \\
\hline & $t$ & & 0.99 & 1.87 & & \\
\hline & $P$ & & $>0.05$ & $>0.05$ & & \\
\hline
\end{tabular}


Table 3 Comparison of DWI results before and after neoadjuvant chemotherapy

\begin{tabular}{|c|c|c|c|c|c|c|}
\hline Indexes & Group & Number of cases & Before chemotherapy & After chemotherapy & $t$ & $P$ \\
\hline \multirow[t]{4}{*}{$\mathrm{ADC}_{\text {min }}$} & Remission & 39 & $0.72 \pm 0.16$ & $1.39 \pm 0.21$ & 15.85 & $<0.01$ \\
\hline & Ineffective & 26 & $0.69 \pm 0.13$ & $0.79 \pm 0.19$ & 2.21 & $<0.05$ \\
\hline & $t$ & & 0.80 & 11.71 & & \\
\hline & $P$ & & $>0.05$ & $<0.01$ & & \\
\hline \multirow[t]{4}{*}{$A D C_{\text {mean }}$} & Remission & 39 & $0.77 \pm 0.19$ & $1.46 \pm 0.23$ & 14.44 & $<0.01$ \\
\hline & Ineffective & 26 & $0.74 \pm 0.17$ & $0.87 \pm 0.13$ & 3.10 & $<0.01$ \\
\hline & $t$ & & 0.65 & 11.86 & & \\
\hline & $P$ & & $>0.05$ & $<0.01$ & & \\
\hline
\end{tabular}

\section{Serum CA199 levels in patients before and after} neoadjuvant chemotherapy

The serum CA199 levels in patients before and after neoadjuvant chemotherapy are presented in Fig. 3. Before treatment, there was no significant difference in CA199 level between the two groups $(p>0.05)$. However, after neoadjuvant chemotherapy, CA199 level in the remission group was markedly lower than that in the ineffective group ( $p<$ $0.01)$.

\section{Discussion}

Neoadjuvant chemotherapy is often used as an adjuvant intervention in the clinical treatment of breast cancer patients $[12,13]$. Before tumour resection or local chemoradiotherapy, the use of neoadjuvant chemotherapy reduces the lesion volume to a certain extent, and prevents the spread of cancer cells, resulting in a positive effect on subsequent treatments $[14,15]$. However, there is a need for more effective methods for the evaluation of patient responses to neoadjuvant chemotherapy. With

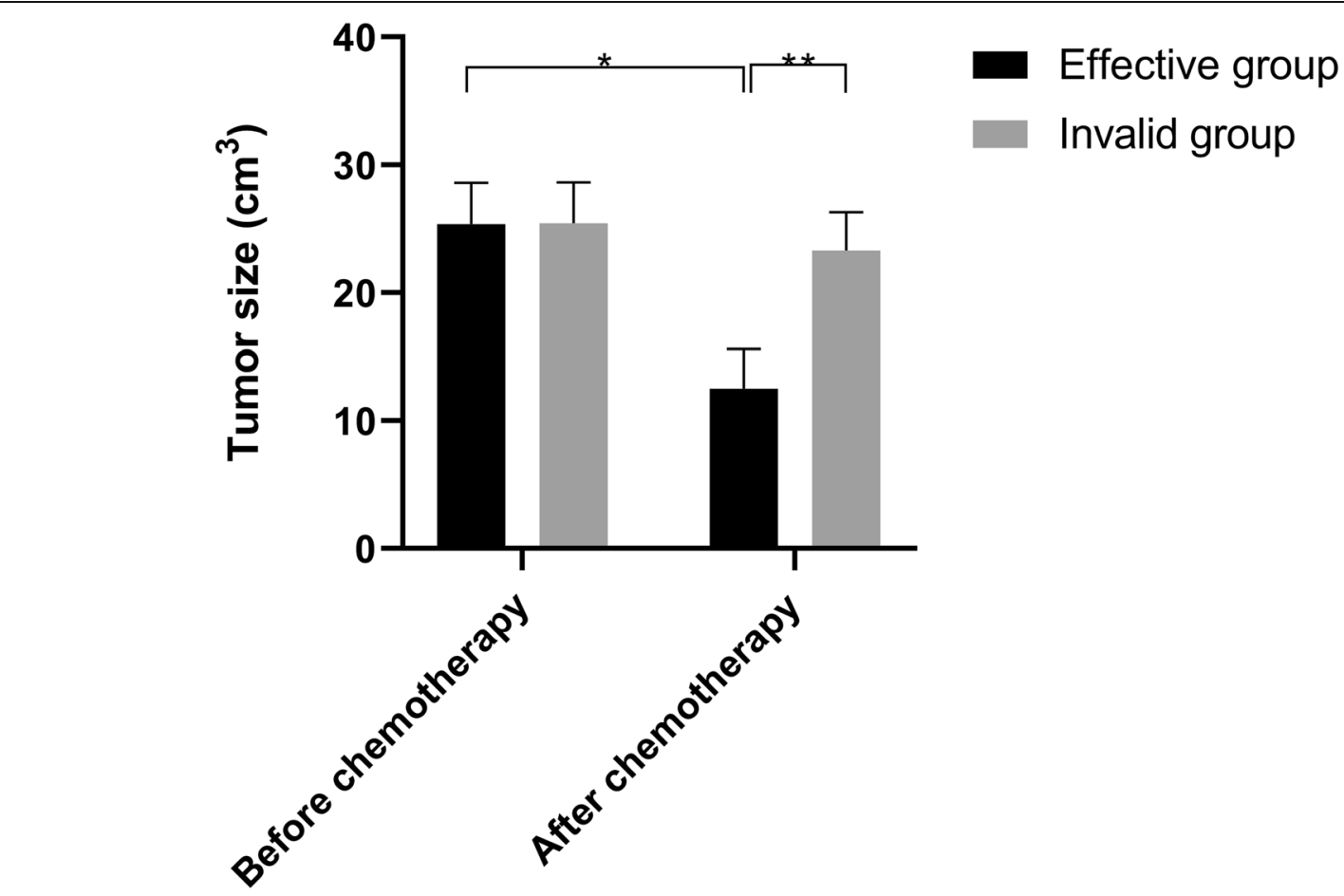
Effective group
Invalid group

Fig. 1 Tumour volume in the two groups before and after neoadjuvant chemotherapy. ${ }^{*} P<0.01$, tumour volume of patients in the remission group before neoadjuvant chemotherapy $\left(25.39 \pm 3.21 \mathrm{~cm}^{3}\right)$ vs tumour volume after neoadjuvant chemotherapy $\left(12.51 \pm 3.09 \mathrm{~cm}^{3}\right)$; ${ }^{*} P<0.01$, tumour volume of patients in remission group $\left(25.39 \pm 3.21 \mathrm{~cm}^{3}\right)$ vs tumour volume of patients in ineffective group $(23.32 \pm 3.01 \mathrm{~cm} 3) \mathrm{after}$ neoadjuvant chemotherapy 


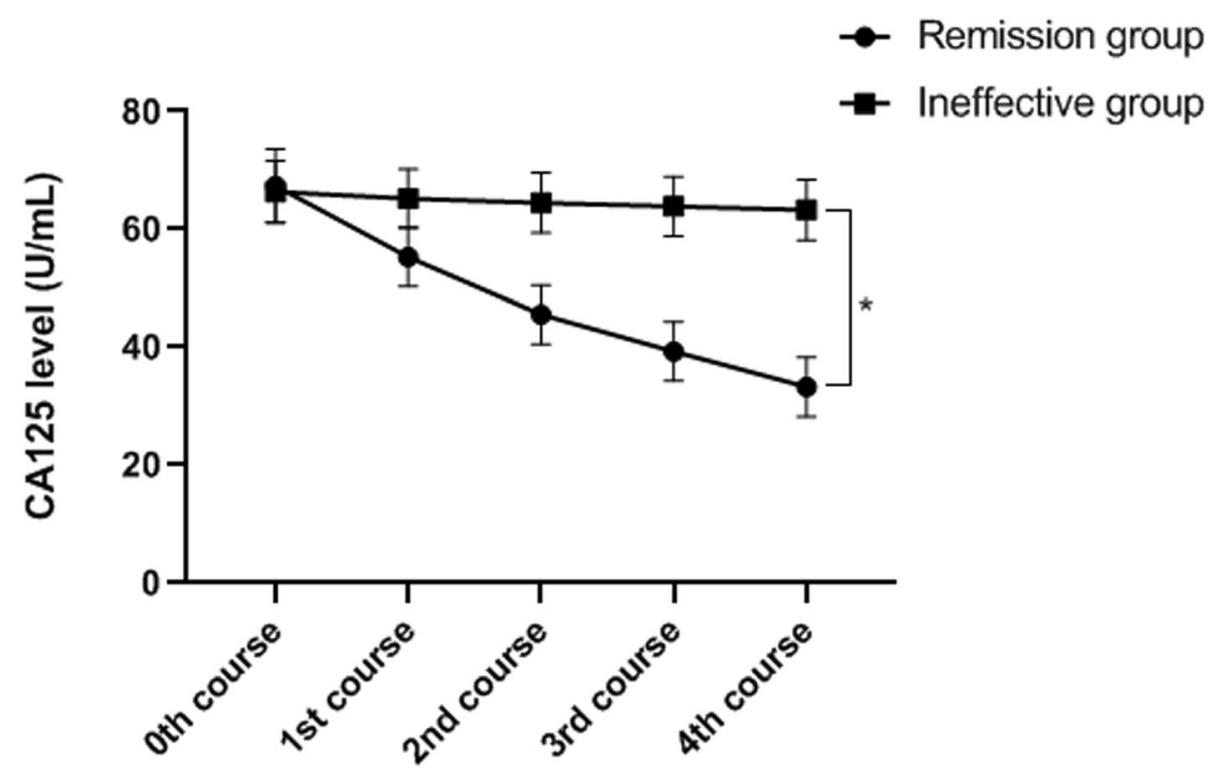

Fig. 2 Serum CA125 levels of patients before and after neoadjuvant chemotherapy. ${ }^{*} P<0.01$, serum CA125 level between the remission group $(33.27 \pm 5.03 \mathrm{U} / \mathrm{mL})$ and ineffective group $(63.27 \pm 5.13 \mathrm{U} / \mathrm{mL}$ after 4 courses of neoadjuvant chemotherapy

advances in the development of imaging diagnostic technology, the accuracy of DCE-MRI and DWI in tumour diagnosis has been continuously improved. Thus, these techniques have been gradually applied in the evaluation of the efficacy of neoadjuvant chemotherapy. The imaging function of DWI directly reflects the lesions in patients based on changes in diffusion of water molecules in the lesions [16]. Studies have shown that the higher the density of pathological cells in tumours, the higher the degree of limitation to the diffusion of internal water molecules. The ADC value obtained by DWI detection can accurately quantify the diffusion value of internal water molecules in the tissue, thereby effectively revealing the degree of tumour lesion in the patient [17]. This study has shown that the results of DCE-MRI and DWI in patients in the remission group after neoadjuvant chemotherapy were significantly different from those before intervention, and they were significantly different from those in the ineffective group. Thus, DCE-MRI and DWI can be reasonably applied for the evaluation of the

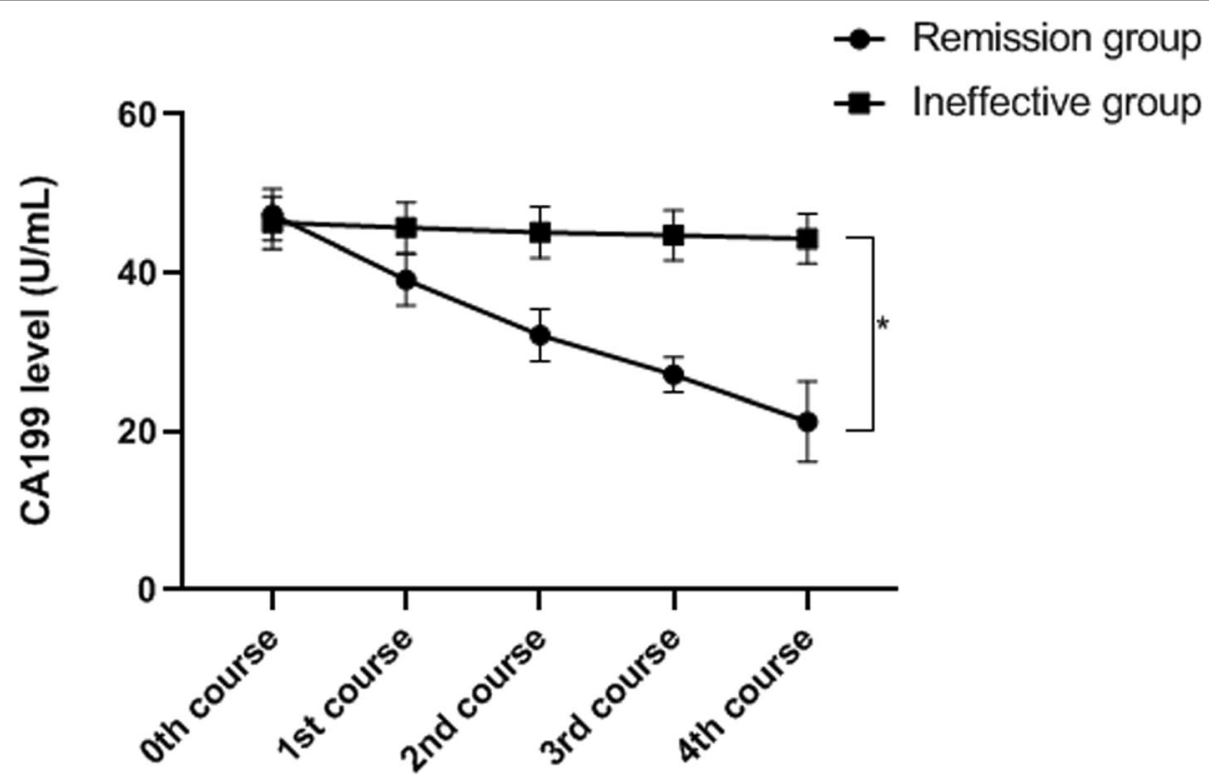

Fig. 3 Serum CA199 levels of patients before and after neoadjuvant chemotherapy. ${ }^{*} P<0.01$, comparison of serum CA199 level of patients (after 4 courses of neoadjuvant chemotherapy) between the remission group $(21.23 \pm 5.03 \mathrm{U} / \mathrm{mL})$ and the ineffective group $(44.29 \pm 3.13 \mathrm{U} / \mathrm{mL})$ 
results of neoadjuvant chemotherapy. Neoadjuvant chemotherapy is a globally-used intervention on cancer patients before tumour resection or targeted therapy [18, 19]. Although diagnostic imaging can directly reflect changes in lesions in patients, it is often unable to effectively determine cancer cell metastasis and small pathological tissues.

Tahmassebi et al. [20] have reported that diagnosis with DCE-MRI and DWI was effective for evaluation of the therapeutic effect of neoadjuvant chemotherapy in breast cancer patients. Studies have shown that CA15-3, CEA, CA125 and CA199 and other cancer-related factors, to a large extent, reflect the state of tumours, which is of great significance in the diagnosis, intervention and clinical follow-up of breast cancer patients [21, 22]. The serum expression levels of CA125 and CA199 in breast cancer patients are usually significantly higher than those in healthy people $[22,23]$. This study showed that the serum levels of CA125 and CA199 in patients in the remission group were significantly reduced during neoadjuvant chemotherapy, and there were significant differences in the serum CA125 and CA199 levels after neoadjuvant chemotherapy between the remission group and the ineffective group. These results indicate that the serum expression levels of CA125 and CA199 can effectively be used to determine the therapeutic effect of neoadjuvant chemotherapy. Although serum CA125 and CA199 levels reflect the progression of breast cancer to an extent, they do not directly reflect the lesions in patients. Moreover, these indexes are associated with some limitations when used to guide subsequent treatments and interventions. In addition, a study has shown that there were significant changes in the serum CA125 levels of patients before and after neoadjuvant chemotherapy [24]. This is consistent with the results of the present study.

\section{Conclusion}

The present study has demonstrated that the imaging diagnostic technique of DCE-MRI and DWI are effective in reflecting changes in lesions in breast cancer patients after neoadjuvant therapy. Moreover, the study has shown that serum levels of CA125 and CA199 reflect the impact of neoadjuvant chemotherapy on patients with respect to risk of cancer cell metastasis and changes in some small lesions. These findings indicate that DCEMRI and DWI, in combination with serum tumour factors CA125 and CA199 can provide more comprehensive and accurate guidance for subsequent clinical treatments of breast cancer patients.

\section{Authors' contributions}

JZ designed the study and drafted the manuscript. YH and JC were responsible for the collection and analysis of the experimental data. XW and HM revised the manuscript critically for important intellectual content. All authors read and approved the final manuscript.

\section{Funding}

Not applicable.

\section{Availability of data and materials}

The datasets used and/or analysed during the current study are available from the corresponding author on reasonable request.

\section{Declarations}

\section{Ethics approval and consent to participate}

This study was approved by the Ethics Committee of Gaomi People's Hospital. Signed written informed consents were obtained from the patients and/or their guardians.

Consent for publication

Not applicable.

\section{Competing interests}

The authors declare that they are no competing interests in this study.

\section{Author details}

${ }^{1}$ Radiological Department, Gaomi People's Hospital, Gaomi 261500, Shandong Province, China. ${ }^{2} \mathrm{CT}$ Radiology, Gaomi People's Hospital, Gaomi 261500, Shandong Province, China. ${ }^{3}$ Department of Electrical and Computer Engineering, National University of Singapore, Singapore 117583, Singapore.

Received: 31 March 2021 Accepted: 10 September 2021

Published online: 18 September 2021

\section{References}

1. Blackley EF, Loi S. Targeting immune pathways in breast cancer: review of the prognostic utility of TILs in early stage triple negative breast cancer (TNBC). Breast. 2019;48:S44-8. https://doi.org/10.1016/S0960-9776(1 9)31122-1.

2. Tagliafico AS, Piana M, Schenone D, Lai R, Massone AM, Houssami N. Overview of radiomics in breast cancer diagnosis and prognostication. Breast. 2020;49:74-80. https://doi.org/10.1016/j.breast.2019.10.018.

3. Nazari SS, Mukherjee P. An overview of mammographic density and its association with breast cancer. Breast Cancer. 2018;25(3):259-67. https://doi. org/10.1007/s12282-018-0857-5.

4. Ocuin LM, Hardacre JM, Ammori JB, Rothermel LD, Mohamed A, Selfridge $\mathrm{JE}$, et al. Neoadjuvant chemotherapy is associated with improved survival in patients with left-sided pancreatic adenocarcinoma. J Surg Oncol. 2020; 122(8):1595-603. https://doi.org/10.1002/jso.26196.

5. Kitamura H, Hinotsu S, Tsukamoto T, Shibata T, Mizusawa J, Kobayashi T, et al. Urologic Oncology Study Group of the Japan Clinical Oncology Group. Effect of neoadjuvant chemotherapy on health-related quality of life in patients with muscle-invasive bladder cancer: results from JCOG0209, a randomized phase III study. Jpn J Clin Oncol. 2020;50(12):1464-9. https://doi. org/10.1093/jjco/hyaa123.

6. Yao SE, Tripcony L, Sanday K, Robertson J, Perrin L, Chetty N, et al. Survival outcomes after delayed cytoreduction surgery following neoadjuvant chemotherapy in advanced epithelial ovarian cancer. Int J Gynecol Cancer. 2020;30(12):1935-42. https://doi.org/10.1136/ijgc-2020-001658.

7. Miyata H, Sugimura K, Yamasaki M, Makino T, Tanaka K, Morii E, et al. Clinical Impact of the Location of Lymph Node Metastases After Neoadjuvant Chemotherapy for Middle and Lower Thoracic Esophageal Cancer. Ann Surg Oncol. 2019;26(1):200-8. https://doi.org/10.1245/s10434-018-6946-z.

8. Salinaro JR, McQuillen K, Stemple M, Boccaccio R, Ehrisman J, Lorenzo AM, et al. Incidence of venous thromboembolism among patients receiving neoadjuvant chemotherapy for advanced epithelial ovarian cancer. Int J Gynecol Cancer. 2020;30(4):491-7. https://doi.org/10.1136/ijgc-2019-000980.

9. Rangarajan K, Pucher PH, Armstrong T, Bateman A, Hamady Z. Systemic neoadjuvant chemotherapy in modern pancreatic cancer treatment: a 
systematic review and meta-analysis. Ann R Coll Surg Engl. 2019;101(7):45362. https://doi.org/10.1308/rcsann.2019.0060.

10. Cortina CS, Gottschalk N, Kulkarni SA, Karst I. Is Breast Magnetic Resonance Imaging an Accurate Predictor of Nodal Status After Neoadjuvant Chemotherapy? J Surg Res. 2021;257:412-8. https://doi.org/10.1016/j.jss.202 0.07.025.

11. Grossman HB, Bellmunt J, Black PC. Can Biomarkers Guide the Use of Neoadjuvant Chemotherapy in T2 Bladder Cancer? Eur Urol Oncol. 2019; 2(5):597-602. https://doi.org/10.1016/j.euo.2019.06.002.

12. Miyazaki C, Shiozawa M, Koike R, Ogihara K, Sasaki Y, Shiba S, et al. Neoadjuvant chemotherapy for primary sarcoma of the breast: a case report. J Med Case Rep. 2019;13(1):289. https://doi.org/10.1186/s13256-01 9-2197-2.

13. Bogani G, Matteucci L, Tamberi S, et al. RECIST 1.1 criteria predict recurrence-free survival in advanced ovarian cancer submitted to neoadjuvant chemotherapy. Eur J Obstet Gynecol Reprod Biol. 2019;237:939.

14. Bownes RJ, Turnbull AK, Martinez-Perez C, Cameron DA, Sims AH, Oikonomidou O. On-treatment biomarkers can improve prediction of response to neoadjuvant chemotherapy in breast cancer. Breast Cancer Res. 2019;21(1):73. https://doi.org/10.1186/s13058-019-1159-3.

15. Liu S, Wang H, Li J, Zhang J, Wu J, Li Y, et al. FZR1 as a novel biomarker for breast cancer neoadjuvant chemotherapy prediction. Cell Death Dis. 2020; 11(9):804. https://doi.org/10.1038/s41419-020-03004-9.

16. Chandramohan A, Siddiqi UM, Mittal R, Eapen A, Jesudason MR, Ram TS, et al. Diffusion weighted imaging improves diagnostic ability of MRI for determining complete response to neoadjuvant therapy in locally advanced rectal cancer. Eur J Radiol Open. 2020;7:100223. https://doi.org/10.1016/j. ejro.2020.100223.

17. Shangguan AJ, Sun C, Wang B, Pan L, Ma Q, Hu S, et al. DWI and DCE-MRI approaches for differentiating reversibly electroporated penumbra from irreversibly electroporated ablation zones in a rabbit liver model. Am J Cancer Res. 2019;9(9):1982-94.

18. Yu JY, Zhang D, Huang XL, et al. Quantitative Analysis of DCE-MRI and RESOLVE-DWI for Differentiating Nasopharyngeal Carcinoma from Nasopharyngeal Lymphoid Hyperplasia. J Med Syst. 2020;44(4):75. https:// doi.org/10.1007/s10916-020-01549-y.

19. Allarakha A, Gao Y, Jiang H, Wang GL, Wang PJ. Predictive ability of DWI/ $A D C$ and DCE-MRI kinetic parameters in differentiating benign from malignant breast lesions and in building a prediction model. Discov Med. 2019;27(148):139-52.

20. Tahmassebi A, Wengert GJ, Helbich TH, Bago-Horvath Z, Alaei S, Bartsch R, et al. Impact of Machine Learning With Multiparametric Magnetic Resonance Imaging of the Breast for Early Prediction of Response to Neoadjuvant Chemotherapy and Survival Outcomes in Breast Cancer Patients. Invest Radiol. 2019;54(2):110-7. https://doi.org/10.1097/RLI. 0000000000000518.

21. Wan $X$, Zhang $H$, Zhang $Y$, Peng $Y$. Metastases to the Breast from Extramammary Nonhematological Malignancies: Case Series. Int I Gen Med. 2020;13:1105-14. https://doi.org/10.2147/JJGM.S276602.

22. Wu H, Wang Q, Guo X, Liu Q, Zhang Q, Huang Q, et al. Frequency of BRCA1 and BRCA2 Mutations in Individuals with Breast and Ovarian Cancer in a Chinese Hakka Population Using Next-Generation Sequencing. Hum Hered. 2019;84(4-5):160-9. https://doi.org/10.1159/000505268.

23. Cai G, Yang X, Ruan X, Wang J, Fang Y, Wei Y, et al. Association of circulating Progesterone Receptor Membrane Component-1 (PGRMC1) with PGRMC1 expression in breast tumour tissue and with clinical breast tumour characteristics. Maturitas. 2020;140:64-71. https://doi.org/10.1016/j.maturita s.2020.06.008

24. Dood RL, Fleming ND, Coleman RL, Westin SN, Lara OD, LaFargue CJ, et al. When Ovarian Cancer Is Not: Characterizing Nonovarian Cancer Pathology in a Laparoscopy-Based Triage System. Int J Gynecol Cancer. 2018;28(8): 1485-90. https://doi.org/10.1097//GC.0000000000001329.

\section{Publisher's Note}

Springer Nature remains neutral with regard to jurisdictional claims in published maps and institutional affiliations.

\section{Ready to submit your research? Choose BMC and benefit from}

- fast, convenient online submission

- thorough peer review by experienced researchers in your field

- rapid publication on acceptance

- support for research data, including large and complex data types

- gold Open Access which fosters wider collaboration and increased citations

- maximum visibility for your research: over $100 \mathrm{M}$ website views per year

At BMC, research is always in progress.

Learn more biomedcentral.com/submissions 